\title{
Dentition Status and Treatment Needs among Type II Diabetic and Non-Diabetic Individuals in Chennai City - A Comparative Study
}

\author{
V Chandrasekhara Reddy ${ }^{1}$, R Kesavan ${ }^{2}$, Navin Ingle ${ }^{3}$
}

\begin{abstract}
Introduction: Patients suffering from diabetes mellitus are known to have increased susceptibility to certain infections. It has significant impact on tissues throughout the body including the oral cavity.

Aim: To assess the dentition status and treatment needs among type II Diabetic and Non-Diabetic individuals in Chennai city. Materials and Methods: A Hospital based Cross-sectional comparative study was conducted among diabetics and non-diabetic population attending the Govt. Stanley hospital in Chennai City. WHO Oral Health Assessment Form (1997) was used to assess the dentition status and treatment needs. The final sample size of the study was 1000 which included 500 diabetics and 500 non-diabetics. Results: The present study revealed not much difference in oral hygiene practices among diabetic and non-diabetics. In the present study, there was no statistical difference in the caries experience among the study subjects. The mean number of teeth missing due to other reasons was $1.40 \pm 2.80$ among diabetics and $0.65 \pm 1.70$ among non-diabetics $(\mathrm{p}<0.0001)$.

Conclusion: There was no significant difference in the prevalence of dental caries among the study subjects. The mean decayed, missing, filled and DMFT scores were similar among diabetics and non-diabetics.
\end{abstract}

Keywords: Diabetics, Dentition status, Treatment needs, Dental caries

${ }^{1}$ Associate professor

Department of Public Health Dentistry

Meenakshi Ammal Dental College

Chennai

${ }^{2}$ Post Graduate student

Department of Public Health Dentistry

Meenakshi Ammal Dental College

Chennai

${ }^{3}$ Professor and Head

Department of Public Health Dentistry

Meenakshi Ammal Dental College

Chennai

\author{
Contact Author \\ Dr. V. Chandrasekhara Reddy \\ drchandu@gmail.com \\ J Oral Health Comm Dent 2011;5(2)79-85
}

\section{INTRODUCTION}

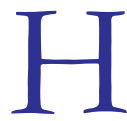
ealth is an invaluable asset. An understanding of health is the basis of all health care (1). Oral self-care is a part of general health and health care comprises wide spectrum of activities ranging from self-treatment, prevention and diagnosis to seeking lay or professional care (2).

Diabetes mellitus is a syndrome of abnormal carbohydrate, fat and protein metabolism that results in acute and chronic complications due to the absolute or relative lack of insulin. There are broadly three general categories of diabetes:

- Type 1, which results from an absolute insulin deficiency

- Type 2, which is the result of insulin resistance and an insulin secretory defect.

- Gestational, a condition of abnormal glucose tolerance during pregnancy (3).

According to WHO any disease with a prevalence of more than $1 \%$ should be considered as a disease of public health importance (1). It is currently estimated that approximately $2.4 \%$ of the population of United States are known diabetics. India, with 32 million diabetic individuals, currently has the highest incidence of diabetes worldwide; these numbers are predicted to increase to 80 million by the year 2030 (4).

Patients suffering from diabetes mellitus are known to have increased susceptibility to certain infections. It has significant impact on tissues throughout the body including the oral cavity. The oral health complications reportedly associated with diabetes include xerostomia, tooth loss, gingivitis, periodontitis, odontogenic abscess, dental caries and opportunistic infections of tongue and oral mucosa (5). Although the oral symptoms of diabetes mellitus were described as back as 1862 by Siefort, till date there is no agreement on the existence and nature of the relationship between the features of diabetes and its 
oral symptoms especially concerning the prevalence of dental caries and periodontal disease (1).

The relationship between diabetes and dental caries, particularly among adults has received far less attention, despite the fact that both diseases are associated with the ingestion of dietary carbohydrates. Here the restricted intake of sugar can have a beneficial effect on the caries rate. Chennai is the $4^{\text {th }}$ largest City in India and the prevalence of diabetes in Chennai is 14\% (4). There are not many studies conducted in Chennai to assess the dentition status of diabetes patients and hence the present study was an attempt to examine the type II diabetic patients and to assess the possible relationship between diabetes mellitus and the development of dental caries.

\section{AIM AND OBJECTIVES \\ Aim}

To assess the dentition status and treatment needs among type II Diabetic and Non-Diabetic individuals in Chennai city.

\section{Objectives}

- To assess the dentition status and treatment needs among type II diabetics and non-diabetics.

- To compare the dentition status of diabetics and non-diabetics.

- To determine whether severity of dental caries is affected by duration of diabetes among diabetics.

\section{MATERIALS AND METHODS}

The source of data was primary. A Hospital based Cross-sectional comparative study was conducted among diabetics and nondiabetic population attending the Govt. Stanley hospital in Chennai City. Ethical clearance was obtained from the Institutional Review Board, Meenakshi Academy of Higher Education and Research, Chennai. Permission to examine the patients and record their personal data was obtained from the concerned authorities of the Hospital. Training exercises were first carried out in the Department of Public Health Dentistry,
Meenakshi Ammal Dental College and Hospital on the out-patients under the guidance of an experienced person. A group of 10 subjects were examined on successive days to assess the consistency of intra-examiner reproducibility. The agreement for most assessments was found to be $85 \%$. For the pilot study, 50 diabetic and 50 non-diabetic subjects were examined for dentition status according to the WHO Basic Oral Health Assessment (1997).

\section{Inclusion Criteria}

- Subjects with Type II diabetes.

- Should have a minimum of 16 functional teeth in the oral cavity

- Individuals in the age group of 35 to 74 years.

- Non-diabetic control group should have no symptoms of diabetes and random blood sugar level less than $200 \mathrm{mg} / \mathrm{dl}$.

- They should be free of major health problems.

- Not taking any medications other than vitamins or occasional analgesics.

\section{Exclusion Criteria}

- History of cardiovascular diseases.

- History of epileptic disorders.

- History of systemic antibiotic administration within the last 3 months.

- Presence of hematological disorders like leukemia.

- Specific conditions like pregnancy, concurrent infections.

- Periodontal surgical treatment 6 months prior to the study.

- Patients with poor dexterity in performing oral hygiene practices.

\section{Sampling Methodology}

To evaluate the proportions of dental caries in people with type II diabetes and nondiabetics with a $\mathrm{p}<0.05$ and $90 \%$ power, the required sample size was calculated.The prevalence of dental caries was calculated from the pilot study. Although the minimum sample size required for each group based on $90 \%$ power was only 377 it was decided to examine 500 individuals to increase the power of the study to $95 \%$.
Therefore the final sample size of the study was 1000 which included 500 diabetics and 500 non-diabetics. Patients attending the diabetic OP and who are fulfilling the inclusion criteria were selected for the study. Non-diabetics (control group) were selected from the individuals accompanying the patients (i.e. attendants, relatives, friends, spouses etc.) and were matched by age and sex. The non-diabetics were tested for random blood sugar level using a glucometer (Acu-Check Active) and subjects with random blood sugar level less than $200 \mathrm{mg} / \mathrm{dl}$ are included in the study.

\section{Collection of Data}

A semi closed ended questionnaire was used to collect information about age, sex and level of education. The study subjects were first explained about the purpose and nature of the study. After obtaining expressed oral concern, the subjects were involved in a face to face interview to get the information regarding their demographic details and to assess their oral hygiene practices. The questionnaire is filled by the examiner to ensure uniformity in data collection and to avoid misinterpretation of the questions by the study subjects. The questionnaire was pretested during the pilot study.

\section{Diabetic assessment}

Date concerning the type of diabetes, level of diabetic control, Duration, complications and familial tendency were retrieved from the medical records of the subjects. Based upon the duration of diabetes the subjects were further divided into:

1 - Less than 5 years

$2-5$ to 10 years

3 - More than 10 years

WHO Oral Health Assessment Form (1997) was used to assess the dentition status and treatment needs. The interview is followed by the clinical examination, which was conducted by a single examiner who was trained and calibrated in the Department of Public Health Dentistry, Meenakshi Ammal Dental College. Subjects were seated comfortably on an 
ordinary chair. Examination was done under natural daylight using plain mouth mirror and CPITN "C" probe. The dentition status was assessed using dentition status and treatment needs.

\section{Statistical analysis}

Statistical analysis was done using SPSS (Statistical Package for Social Sciences) software version 17. Mean values were compared between the study groups using either Student's Independent t-test or One way ANOVA followed by Tukey-
HSD(Highly Significant Difference) Procedure to identify the significant groups. In the present study, $\mathrm{p}<0.05$ was considered as the level of significance.

\section{RESULTS}

\section{Demographic Characteristics of} the Study Population

The final sample size of the study is 1000 which consisted of 500 diabetics and 500 non-diabetics. Table 1 describes the distribution of the study population according to age and gender. Among

\section{Table 1: Distribution of study population according to Age and gender}

\begin{tabular}{|c|c|c|c|c|c|c|c|c|c|c|c|c|}
\hline \multirow{3}{*}{$\begin{array}{l}\text { Age } \\
\text { groups } \\
\text { in years }\end{array}$} & \multicolumn{6}{|c|}{ Diabetics } & \multicolumn{6}{|c|}{ Non-diabetics } \\
\hline & \multicolumn{2}{|c|}{ Male } & \multicolumn{2}{|c|}{ Female } & \multicolumn{2}{|c|}{ Total } & \multicolumn{2}{|c|}{ Male } & \multicolumn{2}{|c|}{ Female } & \multicolumn{2}{|c|}{ Total } \\
\hline & $\mathbf{n}$ & $\%$ & $\mathbf{n}$ & $\%$ & $\mathbf{N}$ & $\%$ & $\mathbf{n}$ & $\%$ & $\mathbf{n}$ & $\%$ & $\mathbf{n}$ & $\%$ \\
\hline $35-44$ & 61 & 24.4 & 83 & 33.2 & 144 & 28.8 & 69 & 27.6 & 96 & 38.4 & 165 & 33 \\
\hline $45-54$ & 102 & 40.8 & 86 & 34.4 & 188 & 37.6 & 116 & 46.4 & 97 & 38.8 & 213 & 42.6 \\
\hline $55-64$ & 63 & 25.2 & 56 & 22.4 & 119 & 23.8 & 44 & 17.6 & 37 & 14.8 & 81 & 16.2 \\
\hline $65-75$ & 24 & 9.6 & 25 & 10 & 49 & 9.8 & 21 & 8.4 & 20 & 8 & 41 & 8.2 \\
\hline Total & 250 & 100 & 250 & 100 & 500 & 100 & 250 & 100 & 250 & 100 & 500 & 100 \\
\hline
\end{tabular}

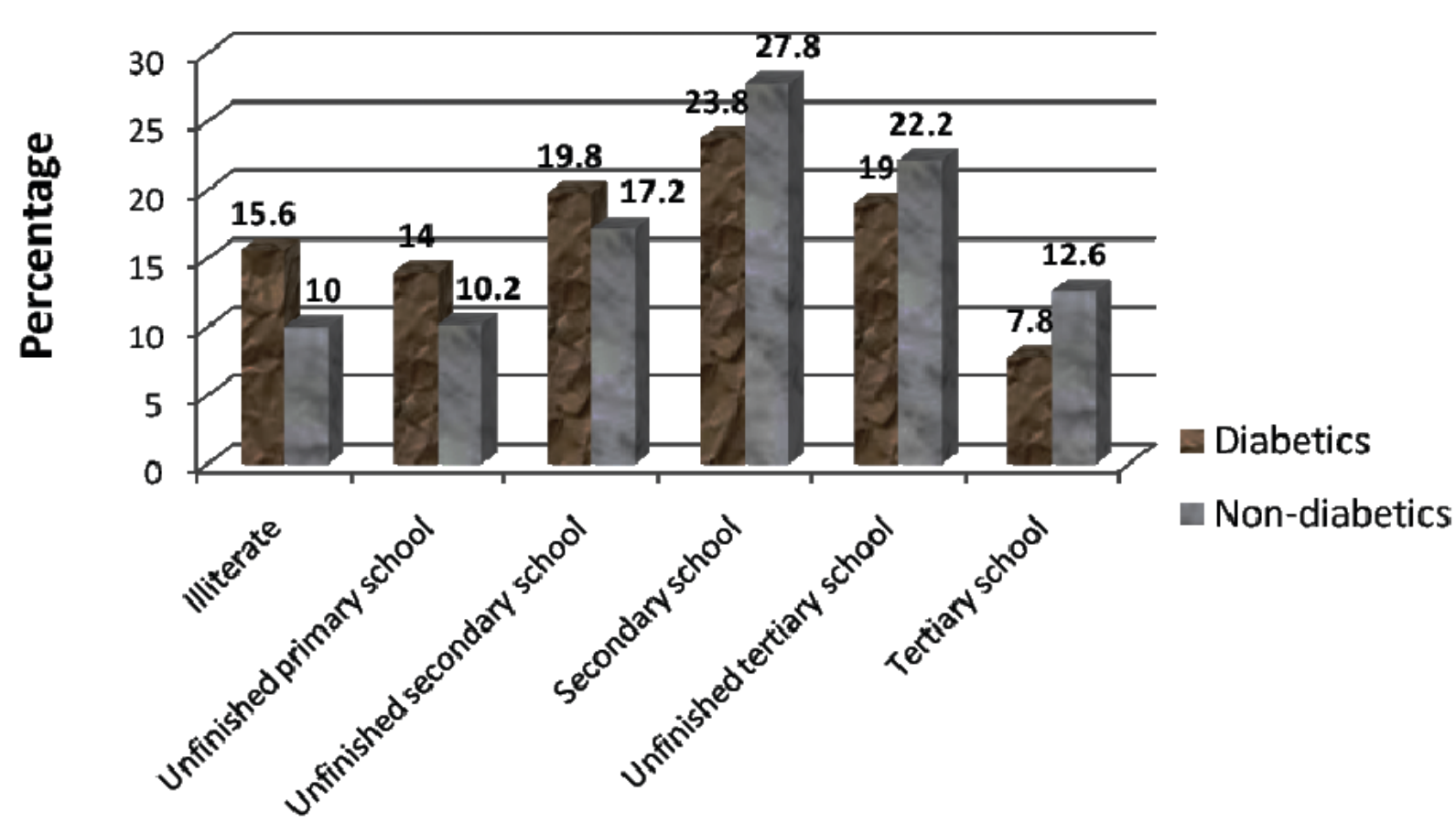

\section{Education}

Figure 1: Distribution of study subjects based upon educational level 
school education and 12.6\% (63) have done graduation.

\section{Distribution of Diabetics Based upon Duration of Diabetes (Table 2)}

The diabetics were further divided into three groups based upon duration. 33.6\% (168) have been diagnosed with diabetes less than 2 years, $32.3 \%$ (161) were diagnosed between $2-5$ years and 34.2\% (171) more than 5 years.

\section{Oral Hygiene Practices Among the Study Population}

Table 3 describes the oral hygiene practices of the study population. More than 95\% (477) of the study subjects use toothbrush and toothpaste to clean their teeth. Around $80 \%$ (402) of them follow

\section{Table 2: Distribution of diabetics based upon duration of diabetes}

\begin{tabular}{|llc|}
\hline Duration & $\%$ & $(\mathbf{n})$ \\
\hline Less than 2 years & 33.6 & $(168)$ \\
2-5 years & 32.2 & $(161)$ \\
More than 5 years & 34.2 & $(171)$ \\
Total & $\mathbf{1 0 0 \%}$ & $\mathbf{( 5 0 0 )}$ \\
\hline
\end{tabular}

Table 3: Oral Hygiene practices among the study Population

\begin{tabular}{|c|c|c|c|c|}
\hline \multicolumn{5}{|c|}{ A. TYPE OF CLEANING } \\
\hline Response & Diabetics \% & (n) & Non -Diabetics \% & (n) \\
\hline Brush & 95.4 & $(477)$ & 97.8 & (489) \\
\hline Finger & 4.6 & (23) & 1.8 & (9) \\
\hline Stick & 0 & (0) & 0.4 & (2) \\
\hline Others & 0 & (0) & 0 & (0) \\
\hline Total & 100 & $(500)$ & 100 & $(500)$ \\
\hline \multicolumn{5}{|l|}{ B. METHOD } \\
\hline Horizontal & 80.4 & $(402)$ & 83.8 & $(419)$ \\
\hline Vertical & 19 & $(95)$ & 15.8 & $(79)$ \\
\hline Circular & 0.6 & (3) & 0.4 & $(2)$ \\
\hline Others & 0 & (0) & 0 & (0) \\
\hline Total & 100 & $(500)$ & 100 & $(500)$ \\
\hline \multicolumn{5}{|l|}{ C. MATERIALS USED } \\
\hline Tooth paste/powder & 99 & (495) & 99.2 & $(496)$ \\
\hline Brick & 0.2 & (1) & 0.2 & (1) \\
\hline Charcoal & 0.8 & (4) & 0.6 & (3) \\
\hline Others & 0 & $(0)$ & 0 & (0) \\
\hline Total & 100 & $(500)$ & 100 & $(500)$ \\
\hline \multicolumn{5}{|l|}{ D. FREQUENCY } \\
\hline Once & 91.8 & $(459)$ & 86.2 & $(431)$ \\
\hline Twice & 8.2 & (41) & 13.8 & $(69)$ \\
\hline More than Twice & 0 & $(0)$ & 0 & (0) \\
\hline Total & 100 & $(500)$ & 100 & $(500)$ \\
\hline
\end{tabular}

Table 4: Dentition status scores among the study population (Mean \pm SD)

\begin{tabular}{|lcccc|}
\hline Status & Diabetics & Non-diabetics & t value & p value \\
\hline Decayed (D) & $1.47 \pm 1.79$ & $1.52 \pm 1.66$ & 0.42 & 0.67 \\
Missing (M) & $0.95 \pm 1.46$ & $1.04 \pm 1.50$ & 0.91 & 0.36 \\
Filled (F) & $0.21 \pm 0.66$ & $0.29 \pm 0.79$ & 1.78 & 0.08 \\
DMFT & $2.63 \pm 2.48$ & $2.84 \pm 2.49$ & 1.35 & 0.18 \\
Missing due to & $1.40 \pm 2.80$ & $0.65 \pm 1.70$ & 5.09 & $<0.0001^{*}$ \\
other reasons & & & & \\
Student's Independent t-test & & & \\
*Very highly significant & & & \\
\hline
\end{tabular}

horizontal method of toothbrushing. Most of them brush their teeth once daily. $8.2 \%$ (41) of diabetics and $13.8 \%$ (61) of non-diabetics brush their teeth twice daily. Mean dentition status score among the study population (Table 4)

The mean number of decayed (D), missing $(\mathrm{M})$, and filled teeth $(\mathrm{F})$ among the diabetics was $1.47 \pm 1.79,0.95 \pm 1.46$ and $0.21 \pm 0.66$, compared to $1.52 \pm 1.66,1.04 \pm 1.50$, and $0.29+0.79$ among non-diabetics. The mean DMFT was 2.63 \pm 2.48 among diabetics and $2.84 \pm 2.49$ among non-diabetics. No statistically significant difference was noted for the above scores. The mean number of teeth missing due to other reasons was $1.40 \pm 2.80$ among diabetics and $0.65 \pm 1.70$ among non-diabetics. The difference noted was statistically very highly significant $(\mathrm{p}<0.0001)$.

\section{Distribution of Study Population According to Treatment Needs (Table 5)}

The mean number of teeth which require one surface filling was $0.58 \pm 0.97$ among diabetics and $0.76 \pm 1.18$ among nondiabetics $(p=0.008)$. The mean number of teeth which require two surface filling was $0.34 \pm 0.65$ among diabetics and $0.35 \pm 0.74$ among non-diabetics $(\mathrm{p}=0.86)$. The mean number of teeth which require pulp care was $0.20 \pm 0.52$ among diabetics and $0.22 \pm 0.64$ among non-diabetics $(p=0.55)$. The mean number of teeth which require extraction was $0.34 \pm 0.86$ among diabetics and $0.23 \pm 0.70$ among non-diabetics $(\mathrm{p}<0.05)$. The mean number of teeth which require RPD was $2.03 \pm 2.62$ among diabetics and $1.57 \pm 2.13$ among nondiabetics $(\mathrm{p}=0.003)$.

\section{Mean Dentition Status Score Among Diabetics Based on Duration of Diabetes (Table 6)}

To identify the significant groups, the diabetics are divided into group 1(less than 2 years), group 2 (2-5years) and group 3 (more than 5 years) based upon the duration of diabetics. The mean number of decayed teeth (D) in group 1, 2 and 3 was $1.49 \pm 1.78,1.39 \pm 1.63$, and $1.53 \pm 1.95$ respectively. The mean number of missing 
teeth $(\mathrm{M})$ in group 1 was $0.71 \pm 1.24$ when compared to $1.09 \pm 1.56$ in group 2 and $1.05 \pm 1.55$ in group 3 . The difference was statistically significant between groups 1 and 2 . The mean number of filled teeth (F) in group 1 was $0.35 \pm 0.87$ when compared to $0.17 \pm 0.56$ in group 2 and
$0.09 \pm 0.46$ in group 3. The difference was statistically highly significant between groups $1 \& 2$ and $1 \& 3$. The mean number of teeth missing due to other reasons in group 1 was $0.68+1.97$ when compared to $1.02 \pm 2.23$ in group 2 and $2.44 \pm 3.59$ in group 3 . The differences were statistically

\begin{tabular}{|c|c|c|c|c|}
\hline Treatment need & Diabetics & Non-diabetics & t value & $p$ value \\
\hline One surface filling & $0.58 \pm 0.97$ & $0.76 \pm 1.18$ & 2.64 & $0.008^{* *}$ \\
\hline Two surface filling & $0.34 \pm 0.65$ & $0.35 \pm 0.74$ & 0.18 & 0.86 \\
\hline Pulp care & $0.20 \pm 0.52$ & $0.22 \pm 0.64$ & 0.60 & 0.55 \\
\hline Extraction & $0.34 \pm 0.86$ & $0.23 \pm 0.70$ & 2.13 & $0.03^{*}$ \\
\hline $\begin{array}{l}\text { Other care needed } \\
\text { (RPD) }\end{array}$ & $2.03 \pm 2.62$ & $1.57 \pm 2.13$ & 3.03 & $0.003^{* *}$ \\
\hline \multicolumn{5}{|c|}{$\begin{array}{l}\text { Student's Independent t-test } \\
{ }^{*} \text { Significant } \\
{ }^{* *} \text { Highly significant }\end{array}$} \\
\hline
\end{tabular}

Table 6: Mean dentition status score among diabetics based on duration of diabetes

\begin{tabular}{|c|c|c|c|c|c|}
\hline Status & $\begin{array}{c}\text { Less than } \\
2 \text { years } \\
\text { (Group1) }\end{array}$ & $\begin{array}{c}2-5 \\
\text { years } \\
\text { (Group 2) }\end{array}$ & $\begin{array}{c}\text { More than } \\
5 \text { years } \\
\text { (Group } 3 \text { ) }\end{array}$ & $p$ value & $\begin{array}{c}\text { Significant } \\
\text { groups }\end{array}$ \\
\hline Decayed(D) & $1.49 \pm 1.78$ & $1.39 \pm 1.63$ & $1.53 \pm 1.95$ & 0.37 & Nil \\
\hline Missing(M) & $0.71+1.24$ & $1.09+1.56$ & $1.05+1.55$ & $0.03^{*}$ & 1 vs 2 \\
\hline Filled $(F)$ & $0.35 \pm 0.87$ & $0.17 \pm 0.56$ & $0.09 \pm 0.46$ & $0.001^{* *}$ & 1 vs 2,3 \\
\hline DMFT & $2.55 \pm 2.14$ & $2.66 \pm 2.40$ & $2.68 \pm 2.83$ & 0.88 & Nil \\
\hline $\begin{array}{l}\text { Missing due to } \\
\text { other reasons }\end{array}$ & $0.68 \pm 1.97$ & $1.02 \pm 2.23$ & $2.44 \pm 3.59$ & $<0.0001^{* \star *}$ & 1 vs 32 vs 3 \\
\hline \multicolumn{6}{|c|}{$\begin{array}{l}\text { One -way ANOVA was used to calculate the } \mathrm{p} \text { value } \\
{ }^{*} \text { Significant } \\
\text { ** Highly significant } \\
{ }^{* * *} \text { Very highly significant } \\
\text { Multiple comparison test by Tukey HSD (Honestly significant difference) procedure } \\
\text { was employed to identify the significant groups at } 5 \% \text { level }\end{array}$} \\
\hline
\end{tabular}

\begin{tabular}{|c|c|c|c|c|c|}
\hline $\begin{array}{l}\text { Treatment } \\
\text { need }\end{array}$ & $\begin{array}{l}\text { Less than } \\
2 \text { years } \\
\text { (Group1) }\end{array}$ & $\begin{array}{c}2-5 \\
\text { years } \\
\text { (Group 2) }\end{array}$ & $\begin{array}{l}\text { More than } \\
5 \text { years } \\
\text { (Group 3) }\end{array}$ & $p$ value & $\begin{array}{l}\text { Significant } \\
\text { groups }\end{array}$ \\
\hline One surface filling & $0.66 \pm 0.99$ & $0.55 \pm 0.91$ & $0.53 \pm 1.00$ & 0.43 & Nil \\
\hline Two surface filling & $0.36 \pm 0.65$ & $0.36+0.65$ & $0.32+0.65$ & 0.78 & Nil \\
\hline Pulp care & $0.25 \pm 0.65$ & $0.15 \pm 0.39$ & $0.19 \pm 0.46$ & 0.20 & Nil \\
\hline Extraction & $0.24 \pm 0.59$ & $0.31 \pm 0.75$ & $0.45 \pm 1.14$ & 0.08 & Nil \\
\hline $\begin{array}{l}\text { Other care needed } \\
\text { (RPD) }\end{array}$ & $1.15 \pm 1.97$ & $1.80 \pm 2.24$ & $3.10 \pm 3.12$ & $<0.0001^{*}$ & $\begin{array}{l}1 \text { vs } 3 \\
2 \text { vs } 3\end{array}$ \\
\hline \multicolumn{6}{|c|}{$\begin{array}{l}\text { One -way ANOVA was used to calculate the } p \text { value } \\
\text { * Very highly significant } \\
\text { Multiple comparison test by Tukey HSD (Honestly significan }\end{array}$} \\
\hline
\end{tabular}

very highly significant between groups $1 \&$ 3 and $2 \& 3$.

\section{Treatment Needs Among Diabetics Based on Duration of Diabetes (Table 7)}

The mean number of teeth which require one surface filling was $0.66 \pm 0.99$ in group 1(less than 2 years), $0.55 \pm 0.91$ in group 2 (2- 5 years) and $0.53 \pm 1.00$ in group 3 (more than 5 years). The mean number of teeth which require two surface filling was $0.36 \pm 0.65$ in group $1,0.36 \pm 0.65$ in group 2 and $0.32 \pm 0.65$ in group 3 . The mean number of teeth which require pulp care was $0.25 \pm 0.65$ in group $1,0.15 \pm 0.39$ in group 2 and $0.19 \pm 0.46$ in group 3 . The mean number of teeth which require extraction was $0.24 \pm 0.59$ in group $1,0.31 \pm$ 0.75 in group 2 and $0.45 \pm 1.14$ in group 3 . No statistical difference was noted for the above scores. The mean number of teeth which require RPD was $1.15 \pm 1.97$ in group $1,1.80 \pm 2.24$ in group 2 and $3.10 \pm 3.12$ in group 3 . The differences were statistically very highly significant $(\mathrm{p}<0.0001)$ between groups $1 \& 3$ and $2 \& 3$.

\section{DISCUSSION}

Diabetes mellitus is a clinically and genetically heterogeneous group of metabolic disorders manifested by abnormally high levels of glucose in the blood. There are many reports in the literature concerning the influence of diabetes on oral health. However, the spectrum of examinations was very narrow and the choice of indices was diverse in character. Therefore the present study was conducted to assess and compare dentition status of diabetic patients with that of nondiabetics, to provide additional information to the existing literature.

\section{Demographic Characteristics of the Study Population}

The study consisted of equal number (250) of males and females in both the diabetic and non-diabetic group. The subjects were selected based upon certain inclusion and exclusion criteria. The age of the study population ranges from $35-75$ years and most of the subjects were in the age group of 45-54 years. This is done to minimize 
bias due to misclassification of diabetes type. More than $95 \%$ of individuals with diabetes who are 45 years of age and older have type II diabetes (6). The effect of type II diabetes on oral health including dental caries can be monitored in these age groups.

Most of the study subjects had secondary school education and few of them are illiterate. Skilled and non-skilled workers constitute majority of the study population. Among female subjects, more than $70 \%$ are housewives.

The diabetics are further divided into different groups, based upon the duration and control of diabetes, to assess the effect of these variables on oral health and to make the methodology and results of this study more comparable with those reported in the literature.

\section{Oral Hygiene Practices Among the Study Population}

The present study revealed not much difference in oral hygiene practices among diabetic and non-diabetics. $95 \%$ of the study subjects use toothbrush and toothpaste to clean their teeth and very few use fingers. In a study conducted by Safia A et al (7) in Jeddah, Saudi Arabia, only $80 \%$ used toothbrush and paste. This may be due to the fact that the present study is conducted in an urban metropolitan city where most of them use toothpaste and toothbrush.

Most of the subjects brushed their teeth once a day and $8.2 \%$ of the diabetics brushed their teeth twice daily which is slightly higher than the study conducted by Abbas Ali Mansour et al (8) in Iraq, in which only $3.7 \%$ brushed twice. In a study conducted by Karikoski et al (9) in Finland, $38 \%$ brushed their teeth twice and the study conducted in Jeddah (7) showed that $46 \%$ brushed their teeth more than once a day. Almost all the subjects follow either horizontal or vertical scrubbing method to brush their teeth. Considering the present results, emphasizing tooth brushing methods and frequency is particularly important among adults with diabetes in Chennai.

\section{Dentition Status}

Clinical and epidemiological studies have been carried out in many parts of the world to investigate the association between diabetes and dental caries. Most studies showed higher, similar or lower caries experience among diabetics than nondiabetics (10).

In the present study, there was no statistical difference in the caries experience among the study subjects. The mean decayed, missing, filled and DMFT scores were similar among diabetics and non-diabetics which are consistent with the findings made by Safia $\mathrm{A}$ et al (7). This is surprising in view of the fact that the lower intake of refined carbohydrates, especially sucrose, and high protein content of the diet make the dietary habits of diabetic subjects clearly less cariogenic than among non-diabetics. This finding, therefore, raises the question as to why adult diabetics develop as many new carious lesions as their healthy counterparts in spite of the restricted diet. Diabetic patients may have more frequent meals than normal subjects and repeated intakes of even small amounts of carbohydrates may be cariogenic (10). A study conducted by Evanthia Lalla et al (11) produced similar results where the mean number of carious lesions was identical in both the groups but the non-diabetic control group had significantly more teeth with restorations. A study conducted by Mattout $\mathrm{C}$ et al (12) also showed more number of restored teeth among nondiabetics. Carious lesions was significantly high among diabetics in studies conducted by Reddy CVK et al (5), Al-Khateeb et al (10), and Hinao J et al (13). In a study conducted by Manjunath P. Puranik et al (1), the mean DMFT was similar in diabetics and non-diabetics but the mean number of decayed and filled teeth was significantly lower among diabetics.

The mean number of teeth missing due to other reasons was significantly higher among diabetics. The "other reason" considered in this study was missing due to periodontal conditions. Although the mean number of missing teeth does not give a direct insight into the periodontal status, it is an important factor in estimating oral health.

When analysing the dentition status among diabetics based upon duration, subjects with more than 5 years of diabetes have significantly more number of missing and filled teeth.

\section{Treatment Needs}

In the present study, the mean number of teeth requiring one surface filling was more among non-diabetics which is consistent with the study conducted by Reddy CVK et al (5). There was no statistical difference among study subjects for teeth requiring two surface filling and pulp care. Mean number of teeth requiring extraction and removable partial denture was significantly more among diabetics.

When analysing the treatment needs among diabetics based upon duration, mean number of teeth requiring removable partial denture was significantly more among diabetics with more than 5 years duration.

The literature on diabetes mellitus is abounding with conflicting results of studies designed to investigate the association between it and dental disease in different communities. This apparent conflict might, however, be more readily acceptable if it was also accepted that the condition of diabetes mellitus itself might be due to genetic and environmental factors which vary from one community to another.

It must be emphasized that the results of this study may not be directly comparable with the results of others. This is due to many differences such as the population size, selection criteria for diabetic and nondiabetic groups, number of examiners, blinding of examiners and intra and intersubject variations in measurements. As the present study was conducted in a government hospital, most of the subjects are of lower socioeconomic status. This could prevent the generalization of the findings to the entire population which can be a limitation of the study. 


\section{CONCLUSION}

In conclusion, there was no statistical difference in the caries experience among the study subjects. The mean decayed, missing, filled and DMFT scores were similar among diabetics and non-diabetics. The mean number of teeth missing due to other reasons was significantly higher among diabetics. Mean number of teeth requiring extraction and removable partial denture was significantly more among diabetics.

\section{REFERNCES}

1. Manjunath P Puranik, Hiremath SS. Oral Health Status and Treatment Needs Among Adult Diabetic and Non-Diabetic Individuals in Bangalore City- A Comparative Study. JIAPHD 2006;8:3137.

2. Chandu GN, Prashant GM, Shivakumar KM, Thippeswamy HM, Sunitha S, Chandrashekhar S. Prevalence of Dental caries and Periodontal Status Among
Diabetic Patients of Davangere City, Karnataka, India. JIAPHD 2007;9:33-36.

3. Jonathan A Ship. Diabetes and oral health: An overview. J Am Dent Assoc 2003;134:4S-10S.

4. Mohan V, Deepa M, Deepa R, Shanthirani CS, Farooq S, Ganesan A, et al. Secular trends in the prevalence of diabetes and impaired glucose tolerance in urban South India-the Chennai Urban Rural Epidemiology Study (CURES-17). Diabetologia 2006;49:1175-78.

5. Reddy CVK, Maurya M. A comparative study to assess the oral health status and treatment needs of diabetics and non-diabetic population attending some of the hospitals in Mysore City. JIAPHD 2008;12:1-14.

6. Tsai C, Hayes C, Taylor GW. Glycemic control of type 2 diabetes and severe periodontal disease in the U.S. adult population. Community Dent Oral Epidemiol 2002;30:182-92.

7. Safia A Al-Attas, Soliman A Oda. Caries experience and selected caries-risk factors among a group of adult diabetics. Saudi Dental Journal 2008;20(3):129-39.
8. Abbas Ali Mansour, Nasear Abd-Al-sada. Periodontal Disease among Diabetics in Iraq. MEDGENMED 2005;7(3):2.

9. Karikoski A, llanne-Parikka P, Murtomaa $\mathrm{H}$. Oral self-care among adults with diabetes in Finland. Community Dent Oral Epidemiol 2002;30:216-23.

10. Al-Khateeb TL, Al-Amoudi NH, Fatani $\mathrm{HH}$ Mira SA, Ardawi MS. Periodontal diseases and caries experience of Diabetic patients in an Arabian community. The Saudi Dental Journal 1990;2(3):9195.

11. Evanthia Lalla, Bin Cheng, Shantanu Lal, Sid Tucker, Ellen Greenberg, Robin Goland, et al. Lamster. Periodontal Changes in Children and Adolescents with Diabetes. Diabetes Care 2006; 29:295-99.

12. Mattout $C$, Bourgeois D, Bouchard P. Type 2 diabetes and periodontal indicators: epidemiology in France 2002-2003. J Periodont Res 2006;41:253-58.

13. Hintao J, Teanpaisan R, Chongsuvivatwong V, Dahlen G, Rattarasarn C. Root surface and coronal caries in adults with type 2 diabetes mellitus. Community Dent Oral Epidemiol 2007;35(4):302-09. 